\title{
Patching together the future of forest modelling: Implementing a spatial model in the 2009 Romeo Malette Forest Management Plan
}

\author{
by Dan Rouillard ${ }^{1}$ and Tom Moore ${ }^{2}$
}

\begin{abstract}
We describe a pilot project on the Romeo Malette Forest in northeastern Ontario that used a spatially explicit strategic model as an element of the hierarchical modelling process used in forest management planning. We integrated 2 different and slightly overlapping modelling tools, the traditional aspatial Strategic Forest Management Model (SFMM) and the newer spatial Patchworks model, to form a comprehensive decision support system for planning. Results from the conventional modelling approach using only SFMM served as comparison. The pilot project's goals included satisfying Ontario's rigorous planning and public consultation requirements, addressing technical issues associated with using 2 separate models, and engaging planning team members in the decision-making process. Implementation of a new technology (spatial modelling) into a highly regulated organizational process presented the planning team with a series of challenges. For example, the higher resolution of the data used for the Patchworks model and changes in conventional concepts and procedures required that the planning team adjust and adapt its approach. One clear advantage of the combined approach was that the long-term effects of spatial and operational adjustments, such as landscape-level policies or harvest block deferrals, were evaluated comprehensively and immediately, leading to greater confidence that the forecast outcomes are sustainable. The hierarchical-spatial modelling process used in this pilot provides a significant improvement to forest management planning and results in improved confidence in the overall sustainability of the long-term management direction. The lessons learned have provided a base for future planning teams to take advantage of the many benefits of a decision support system that includes spatial modelling.
\end{abstract}

Key words: forest management planning, spatial modelling, decision support, Patchworks

\section{RÉSUMÉ}

Cet article décrit un projet pilote réalisé dans la Forêt Romeo Malette située dans le nord-est de l'Ontario au cours duquel un modèle stratégique très détaillé au niveau spatial a été utilisé en tant quélément d’un processus de modélisation hiérarchique employé en planification de laménagement forestier. Nous avons intégré deux outils de modélisation différents qui se chevauchent légèrement, un modèle traditionnel sans fonction spatiale Strategic Forest Management Model (SFMM) et un modèle spatial plus récent Patchworks, afin de constituer un système global d’aide à la décision dans le cas de la planification. Les résultats obtenus selon l'approche conventionnelle de modélisation au moyen seulement du SFMM ont servi à des fins de comparaison. Les objectifs du projet pilote visaient à répondre aux exigences rigoureuses en matière de planification et de consultation publique en Ontario, à répondre aux questions techniques associées à l'utilisation des deux différents modèles et à impliquer les membres de léquipe de planification dans le processus de prise de décision. Limplantation d'une nouvelle technologie (la modélisation spatiale) au sein d'un processus organisationnel sévèrement réglementé, a constitué pour léquipe de planification une série de défis. Par exemple, la résolution plus accentuée des données utilisées dans le modèle Patchworks et les modifications des concepts et des procédures habituelles ont obligé léquipe de planification à s'ajuster et à adapter son approche. Un avantage marquant de l'approche combinée a été que les effets à long terme des ajustements spatiaux et opérationnels, comme les politiques au niveau de lécosystème ou le report dans le temps de la récolte de certains blocs, ont été évalués globalement et immédiatement, le tout menant à une plus grande certitude de la durabilité des prévisions obtenues. Le processus hiérarchique de modélisation spatiale utilisé au cours de ce projet constitue une amélioration significative de la planification de l'aménagement forestier et a résulté en une certitude accrue de la durabilité générale de lorientation à long terme d’aménagement. Les leçons retenues représentent une base pour les futures équipes de planification montrant qu'il faut tirer profit des nombreux bénéfices d’un système d’aide à la décision qui comprend la modélisation spatiale.

Mots clés : planification de l'aménagement forestier, modélisation spatiale, aide à la décision, Patchworks

\footnotetext{
${ }^{1}$ Forest Management Branch, Forest Analysis and Modelling Unit, OMNR, 70 Foster Drive, Suite 400, Sault Ste. Marie, ON P6A 6V5

${ }^{2}$ Spatial Planning Systems, Box 1389, Deep River Ontario K0J 1P0
} 


\section{Introduction}

As forest managers have started to incorporate concepts of ecosystem-based management, issues of pattern and process across the landscape have become increasingly important. This change has led to the development of spatial management policies, which have further led to demand for better spatial planning tools from independent forest auditors, environmental non-government organizations, and forest practitioners. This is exemplified by Condition $45(\mathrm{~d})$ of the Class Environmental Assessment Approval for Forest Management on Crown Lands in Ontario (OEAB 2003), which requires the Ontario Ministry of Natural Resources (OMNR) to maintain and further develop methodologies for forest management planning that support the use of spatial modelling, and by the Forest Stewardship Council's national boreal certification standards, which stipulate that forest condition and the results of operational activities are spatially depicted over the long-term planning horizon (Section 6.3.1; FSCWG 2004). Clearly, there is a growing eagerness on the part of government and stakeholders to incorporate spatial modelling into forest management planning. This eagerness is evident despite questions and design issues about how the tools and methods fit within the existing and well-developed planning frameworks now in use across Canada. Spatial modelling introduces substantially greater detail to the planning process.

Here we examine the implementation of spatial forest modelling technology in the development of the 2009 forest management plan for the Romeo Malette Forest in northeastern Ontario. To begin our discussion, we first describe the classical frameworks for dealing with large decision-making problems. Then we describe the use of a spatially explicit strategic model, in a hierarchical process, in the preparation of the forest management plan for the Romeo Malette Forest (McPherson et al. 2008, this issue). The modelling approach used in this pilot project integrates 2 different and slightly overlapping modelling tools to form a comprehensive decision support system for forest management planning. The seemingly tidy correspondence of decision hierarchy, planning requirements, and models is complicated by the need to satisfy the rigorous planning and public consultation requirements of Ontario's forest management planning approach, address technical issues associated with using 2 separate models, and engage stakeholders in the decision-making process. We conclude with a discussion of challenges yet to be addressed and lessons learned.

\section{Hierarchical Planning Framework}

The decision science literature has long characterized the decision-making process as a hierarchy, whereby decisions could be classified into 3 categories: strategic, tactical, and operational (Anthony 1965). Strategic planning addresses overall resource allocation, tactical planning details the efficient use of those resources, and operational control details how each individual activity will be scheduled and carried out.

It is difficult to combine these 3 levels of decisions in a single process. For anything other than simple situations, the limits of being able to consider all factors simultaneously hampers a decision-maker's ability to deal with the system as a whole (Simon 1972). The hierarchical framework is thus essential because it separates each level of the planning hierarchy into distinct decision processes and addresses them in appropriate detail. Levels of the hierarchy are integrated by downward and upward flows of information between the separate decision processes. The result is a decomposed and simplified decision-making process with each level having its own uniquely characterized decision problem. The characteristics of each level vary with the scope of the decisions, type or level of management participation, the degree of aggregation of the required information, the timeframe in which decisions are to be made, and uncertainty and risk associated with the outcomes (Anthony 1965).

The forest management planning process in Ontario fits well into the structured decision-making process suggested by Anthony (1965). The Forest Management Planning Manual for Ontario's Crown Forests (FMPM; OMNR 2004) prescribes the requirements for Ontario's forest management planning system and these requirements can be characterized in terms of the 3 categories of the hierarchical decisionmaking framework.

At the strategic planning level, the decision problem is concerned with long-term, large-scale resource allocations. Information is typically highly aggregated and involves a high degree of uncertainty. The forest management planning requirements at this level involves the development of the long-term management direction (LTMD). The long-term management direction includes the development of a management strategy that balances the achievement of management objectives. The management strategy provides direction for the levels of access, harvest, renewal and tending activities required to achieve the desired forest and benefits. A decision support system-including analytical methodologies, models and tools regarding forest regulation, social and economic assessment, and landscape biodiversity management-is used to develop the management strategy and includes 160-year projections for forest condition and quantifiable management objectives.

The management strategy associated with the LTMD serves as the primary harvest regulation instrument. The amount of allowable harvest for the first 10-year period of the plan is regulated by area and, as such, the FMPM requires that a stratum-based harvest schedule also known as the available harvest area (AHA) be determined. The AHA specifies the average annual area available for harvest through time, by stratum (using standard species associations known as forest units) and age class. The FMPM stipulates that the allocated harvest area cannot exceed the AHA for any forest unit. In conventional modelling approaches, the AHA is used to guide and constrain tactical planning decisions.

At the tactical level, the decision problem is concerned with middle-term and medium-scale decisions regarding the most effective use of the available resources determined at the strategic level. Information is typically moderately aggregated and the degree of uncertainty is moderate. The forest management planning requirements at the tactical planning level include the identification of primary road corridors and the development of a 10-year operational plan. The operational plan includes the specific identification of areas selected for operations (harvest, renewal, and tending) for the 10-year period with detailed operational prescriptions for the first 5year period.

At the lowest level of the decision-making hierarchy, operational control decisions are made that deal with how each 
activity defined in tactical planning will be carried out. These decisions are short-term, utilize detailed information and involve a relatively low degree of uncertainty. Operational decisions are generally not addressed in forest management planning requirements; rather they are addressed in the planning requirements for annual work schedules due to the need for immediate site inspections and approvals. Annual work schedules include forest operations prescriptions and the detailed project planning required prior to the implementation of forest operations. In Ontario, finer-scale operational decisions related to scheduling of weekly or monthly activities, such as crew and machinery, are not part of the regulated planning process.

An important consequence of the hierarchical planning approach is the opportunity to use separate models and decision support tools at each level of the hierarchy (Gunn 2005). In this arrangement, models used at the top end of the hierarchy would be based on highly aggregated data and used for long-term analysis. These models would then provide appropriate constraints for models used at lower levels in the hierarchy to explore shorter time periods in much greater detail. The coherence of the planning system is contingent on the assumptions made in the upper levels being held consistent at the lower levels.

\section{Conventional Modelling Approach}

In Ontario, the conventional modelling approach is a 2-stage, single-model decision support system. Despite policy that allows the use of other strategic forest models, the Strategic Forest Management Model (SFMM) has been the standard in Ontario since 1997. SFMM is a linear programming model (model III formulation) developed by OMNR and adapted to suit provincial forest management planning requirements as they have evolved. It is intended for strategic-level planning for large forest areas, and can be used to project forest development through time (Davis 1999). SFMM is an aspatial model; that is, the spatial reference of model inputs such as the forest inventory are lost as the model is compiled, modelling processes are not governed by explicit spatial constraints or objectives, and outputs have no spatial reference.

Within the forest management plan (FMP) decision-making framework, SFMM is used to support strategic-level decisions about sustainable levels of management activities. SFMM models are highly aggregated formulations that do not include explicit spatial objectives. The impact of spatial constraints such as marten cores or caribou mosaics can be addressed in a limited way using gross area deferrals. The primary output used for tactical planning is the AHA. Tactical level planning requirements (e.g., cut-block selection) are typically addressed manually, using relatively simple GIS technology to locate and allocate short-term treatment options that are consistent with the AHA produced during strategic modelling. Thus, outputs from the strategic model provide targets for the GIS allocation and a summary of the final GIS allocation is fed back into the strategic model to assess the effects on objectives and any variance from the strategically defined harvest area. Fig. 1 provides a graphical overview of this conventional modelling approach.

At the strategic planning level, SFMM is used to develop management objectives and a management strategy that achieves a balance of desired forest-level benefits. SFMM is

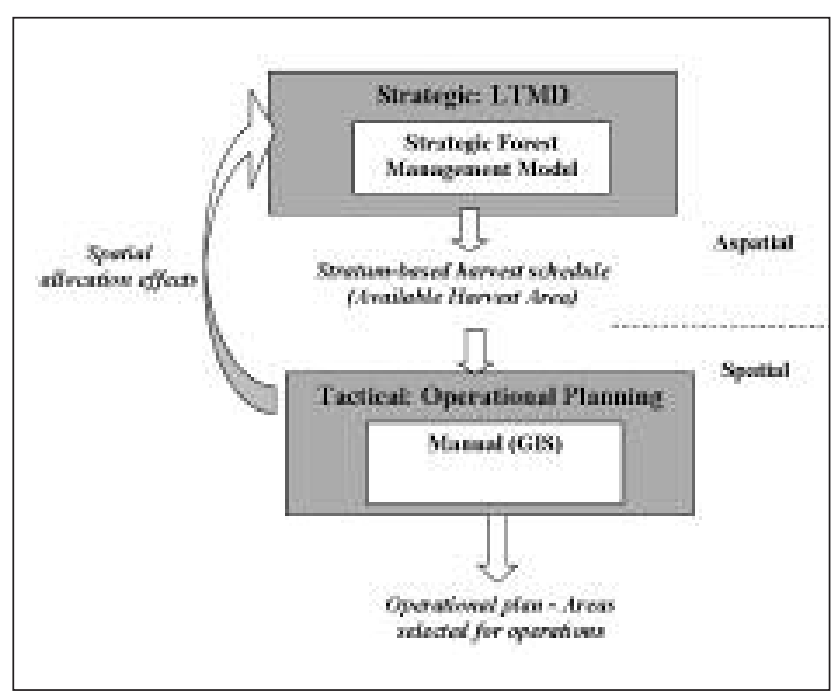

Fig. 1. Conventional hierarchical modelling approach used in Ontario. (LTMD - long-term management direction)

used to address several specific FMP analytical requirements, such as conducting natural benchmark investigations (i.e., an analysis of how the forest is expected to develop in the absence of human intervention), scoping analyses to narrow the breadth of potential objectives, and incorporating expected rates of natural depletions. Fulfilling these analytical requirements involves iterative analyses that typically require modelling assumptions to be adjusted and models re-solved many times. This analysis ultimately contributes to the definition of desired forest conditions and expected benefits.

Once the planning team agrees on the desired benefits, the associated levels are used to develop the LTMD, which becomes the benchmark used in the assessment of sustainability. The management strategy is represented by a modelling scenario that includes a set of management activities the outcome of which achieves a satisfactory balance of objectives as assessed by the planning team. The primary output of strategic planning is the AHA for the first 10 years of the plan, which describes the area available for harvest by strata (forest unit and age class). This is used at the tactical planning level to guide the spatial allocation of harvest areas. Variation in this harvest schedule is permitted provided the overall harvest area by forest unit for the license area is not exceeded.

The role of the tactical planning process is to explicitly identify the on-the-ground sequence of management actions required to fulfill the long-term management direction; in other words, find the forest stands that match the harvest profile provided by the AHA. It is at this stage that the reality of spatial arrangement must be reconciled. The spatially explicit layout must not only address the harvest profile, but must also consider spatial landscape policies associated with forest management guides (i.e., natural disturbance pattern emulation, identified natural resource features, land uses, values, and other forest uses such as remote tourism and trap lines). As well, planners must also be cognizant of the costs of their proposed pattern of operations, with specific regard to existing and proposed industrial infrastructure (e.g., roads, mills).

During tactical planning, spatial allocation issues often limit the ability to allocate forest areas according to the AHA 
by forest unit. Infeasibility of the AHA is commonly attributed to spatially oriented constraints, such as natural disturbance pattern emulation objectives, spatial habitat provisions, infrastructure and accessibility, and other site-specific logging chance factors that cannot be addressed in strategic modelling using SFMM. In some cases, constraints are adjusted or added to the strategic model to encourage a more feasible harvest schedule. However, this practice is often avoided because additional constraints in SFMM can result in substantial changes to the AHA that would invoke a complete revision of the tactical plan.

The FMPM (OMNR 2004) specifies that areas selected for operations are assessed for their potential effect on achieving progress towards the LTMD. Conventionally, the selected areas are simulated in the SFMM model for the operational planning period and the effects are assessed over the strategic planning horizon. This assessment examines the potential effect of deviations from the AHA on long-term indicators of sustainability. Where this is significant, the operational plan is adjusted (FMPM Section 1.3.10).

Though the conventional approach works reasonably well in practice, a number of shortcomings have potential consequences for long-term sustainability. These include:

1) Limited ability to explore tactical options:

- Although the process is designed to be iterative (issues from the tactical level feed back to the strategic), the manual allocation process limits the ability to adjust and respond to changes at the strategic level. Typically, strategic direction is held constant early in the planning process and can unduly constrain tactical planning (i.e., many other possible AHA formulations may achieve the same or similar desired conditions but are not considered). The result is that sub-optimal tactical solutions are accepted and rationalized rather than adjusting the strategic solution.

- Tactical planning requires that many tactical and strategic issues are considered simultaneously during the selection of operating areas. The manual process of selecting harvest blocks is painstaking and limits exploration of the full range of tactical options. The likelihood that the resulting operational plan provides an optimal solution to the tactical and strategic considerations for the operating period is very low.

2) Limited ability to consider long-term spatial planning issues:

- Although the conventional process requires the planning of harvest activities and ensures compliance with the spatial objectives over the first 10 years, no mechanism is in place to ensure that spatial objectives not represented in strategic analyses are achievable beyond the initial operating period. Thus, there is no way of knowing whether spatial objectives such as natural disturbance patterns are achieved beyond the 10-year plan.

- The feasibility of the operational program is, to a large extent, driven by cost. The spatial arrangement of harvest areas influences operational factors such as haul distances, the amount of road construction, and dispersal of operations, which affects the extent of road maintenance and the frequency of machinery and crew movement. Operational costs associated with these factors can vary and perhaps increase significantly over time if the least expensive areas are harvested first.
Without developing a long-term spatially explicit strategy (e.g., spatial allocation), future operating costs cannot be estimated.

- Incorporating long-term spatial objectives and operational feasibility may also affect the long-term indicators of sustainability but again there is no way of estimating the effects without developing a long-term spatially explicit strategy.

- Wildlife habitat assessment in SFMM is based on summing the areas of stands that meet criteria of preferred habitat without considering juxtaposition of food and cover among other spatially relevant criteria. Applying spatially explicit forecasting in management planning would benefit this and other important values (such as biodiversity, watershed assessments, fire and insect risk).

- Ecosystem function is rapidly becoming an important consideration in forest management planning, and is linked to species composition, structure, and pattern. The SFMM model provides reasonable estimates for composition and structure, but is not able to consider pattern in ways that are important to landscape ecologists.

The current hierarchical process is repeated on a 10-year cycle, and at each update the spatial design issues are reconsidered. However, the system is not set up to detect and prevent potential longer-term issues of meeting spatial design goals. This may lead to a future situation where the spatial goals cannot be met, the long-term sustainability goals will be compromised, or both.

\section{Pilot Implementation Approach}

The hierarchical modelling approach used in the pilot study is a 2-stage, 2-model approach, using SFMM and Patchworks. SFMM is useful to address specific FMPM requirements and has rapid solve times, giving it an important role in establishing the natural benchmarks and scoping, leading to the definition of desired forest and benefit levels for the FMP. Here, the primary output from SFMM is a set of strategic-level management targets for Patchworks. Patchworks is a strategic, spatially explicit model that incorporates a large degree of detail over the same long time horizons as SFMM (SPS 2008). Patchworks output includes a spatially detailed harvest sequence with many operational considerations, providing an advanced template for further manual adjustments. Fig. 2 provides an overview of the hierarchical decision framework and modelling approach used for the pilot Romeo Malette FMP.

The hierarchical implementation of SFMM and Patchworks takes advantage of the fact that SFMM is very well suited to scoping and coarse trade-off analyses and has functionality specifically designed to address Ontario's planning requirements, particularly with respect to setting renewal objectives. Another important benefit of the hierarchical arrangement of the 2 models is that SFMM provides Patchworks with an already scoped or narrowed solution space. This advantage has been identified by others; for example, Boston and Bettinger (2001) found that a 2-stage modeling approach is superior to a 1-stage approach and, in their effort to develop a more efficient management planning process, concluded that a tactical heuristic model may benefit from guidance provided by a linear programming solution.

As a spatially explicit model, Patchworks provides a detailed depiction of the location of stand-level features and proposed management actions. Advantages to the extra effort 


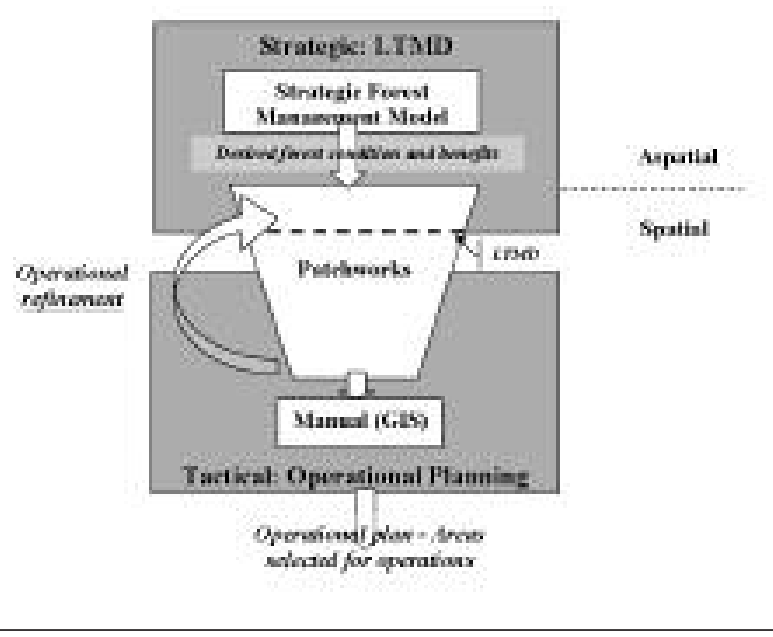

Fig. 2. The hierarchical modelling approach modified to accommodate both aspatial and spatial models. (LTMD - long-term management direction]

of tracking stand-level detail are several, but the principal one is that it opens the possibility to embed spatial and operational policies within a long-term strategic management context, thus avoiding some of the previously discussed shortcomings of the current hierarchical approach. Thus, to the extent that spatial policy issues can be embedded within the strategic planning framework, the model can be used to consider strategies that balance both strategic and tactical or operational issues.

The ability to address location issues within the modelling approach facilitates the creation of forest development plans that have reasonable operating characteristics and are logistically feasible. Although cost is not the only motivation in operational planning, it does influence the patterns of operations that are affordable and thus likely to be carried out. Conversely, expensive or operationally frivolous plans would have a very low likelihood of being implemented (see Fig. 3). Patchworks can include spatial and economic attributes that track some of the main factors of operating costs (e.g., harvest and treatment costs, road construction, location and budgets). These factors are integrated within a strategic planning framework and long-term sustainability options are automatically balanced.

In the pilot hierarchical modelling approach, Patchworks spanned the gap between strategic and tactical planning. The strategic direction narrowed in SFMM was the starting point for using Patchworks to conduct a trade-off analysis with the addition of spatial objectives such as natural disturbance pattern emulation, habitat provision, transportation and operational harvest block configuration. A strategic-level Patchworks solution was completed once the planning team was satisfied with the balance of both the long-term spatial and non-spatial management targets.

A number of factors were used in both the aspatial and spatial models (Table 1). In SFMM, these factors are incorporated in the general template of the model, with the single goal of optimizing timber value subject to multiple constraints. The Patchworks model has a generalized mechanism to express multiple goals. Goals (which allow deviation from targets) are preferable to constraints since they allow more options and thus greater flexibility to find performanceimproving configurations. Where resources are limited, the solution finding algorithm can make cost-effective adjustments by foregoing a small improvement in one goal to achieve a large increase in another. To enforce a high priority on meeting important goals (such as the retention of oldgrowth forest types), preference weighting values can be adjusted to appropriately high levels for preferred objectives.

In the pilot study, the spatial controls included objectives for protecting core marten habitat, meeting cutblock opening size targets, and moving towards a natural disturbance pattern on the landscape. Protection of pine marten habitat was achieved by identifying areas where harvest would be deferred for up to 60 years. These areas were selected by the planners in consultation with area biologists and would be available for future harvest (after 60 years). The cutblock size frequency followed provincial policy that $80 \%$ of the cutblocks would be less than 260 hectares. The natural pattern emulation guide (OMNR 2001) required moving towards a distribution of disturbance patches (young forest less than 20 years old) that is similar to the template based on local fire history. The mechanisms that Patchworks uses to implement these spatial controls are described in Moore and Tink (2008, this issue).

The road access and transportation cost tactical objectives influenced harvest location. Simply put, if a stand could not be accessed by a road, then it was not eligible for harvest. The modelling database included a fully connected network of road segments, with each segment having identified costs for construction (\$), maintenance (\$/period) and hauling $\left(\$ / \mathrm{m}^{3}\right)$. If a road segment already existed, then the construction cost was zero. Road segments selected and used for the first time incurred a construction cost. Maintenance costs describe the cost of keeping the road segment open for one planning period, and represent the costs of brushing, ploughing, and repair. Hauling costs describe the cost per cubic metre for a round-trip haul (getting the truck to the harvest site and back). The database also identified the closest road to each stand, and the model accumulated the costs involved when a harvest occurred from a stand to the initial road segment and then in a connected flow to the mill. Goals were established to limit the budget available for road construction and maintenance, as well as hauling.

The use of budget limits for the road cost objectives ensured that the model would progressively access the wood supply in a realistic manner. The effect of implementing a road budget is that stands may not be harvested in an order that strictly maximizes aspatial wood supply. To provide a continuous flow of wood, stands that may not be of prime age but are accessible will be harvested instead. The consequence of these substitutions is quite likely a reduced sustainable harvest relative to the non-spatial model; however, the model will dynamically adjust the harvest schedule and road access pattern over the entire planning horizon to best achieve a balance among management goals.

Integration of Patchworks in the FMP decision-making process occurs at the strategic planning level. At this stage of planning, management targets that were defined using SFMM were incorporated into Patchworks with the aim of balancing desired forest condition and expected benefit levels given spatial and operational management objectives. Ini- 
A

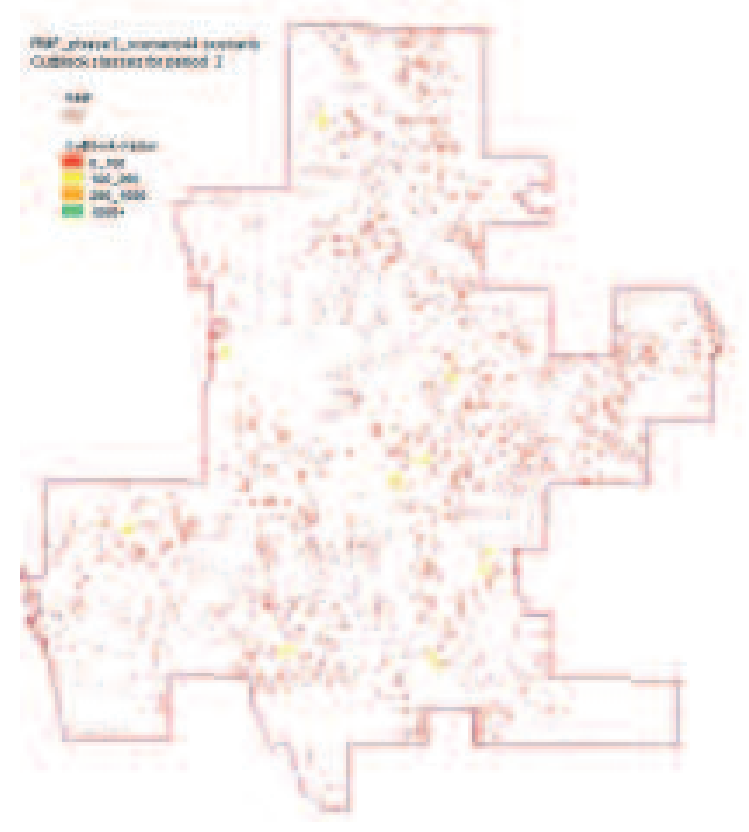

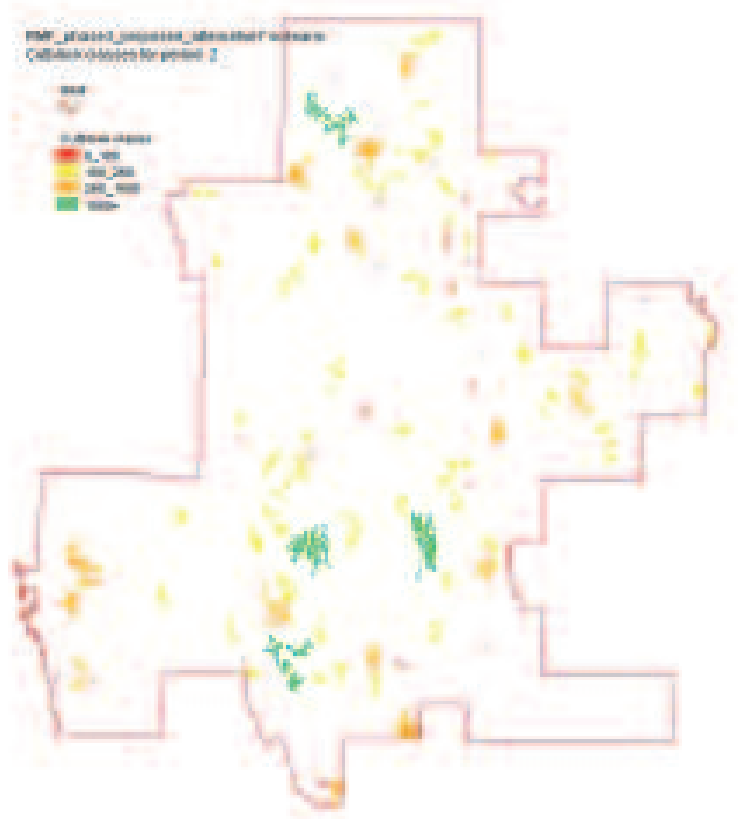

Fig. 3. Harvest allocation for the Romeo Malette Forest for the second 5-year period from (A) optimizing the long-term non-spatial objectives without regard to spatial pattern (i.e., spatially unconstrained) and (B) including spatial and operational goals (i.e., spatially constrained]. Identical long-term sustainability targets were applied in both scenarios though the achievement of goals varied. Not shown is the road network required to deliver harvested wood to the mill, which was substantially larger and more expensive in the spatially unconstrained scenario.

Table 1. Goals and constraints included in the 2 strategic planning models used for the Romeo Malette Forest pilot implementation project. The Strategic Forest Management Model (SFMM) allowed one goal and multiple constraint while Patchworks implemented many of the constraints as goals with suitably high weights.

\begin{tabular}{|c|c|c|c|}
\hline Objectives & Factor considered & $\begin{array}{l}\text { Modelling approach } \\
\text { SFMM }\end{array}$ & Patchworks \\
\hline \multirow[t]{7}{*}{ Non-spatial } & Maximize harvest volume by species group & $\begin{array}{l}\text { Goal (subject to } \\
\text { flow constraints) }\end{array}$ & $\mathrm{Goal}^{\mathrm{a}}$ \\
\hline & Retain level of mature and old-growth forest ( $70 \%$ of natural scenario) & Constraint & Goal $^{\mathrm{a}}$ \\
\hline & Apply upper limit on silvicultural expenditures & Constraint & $\mathrm{Goal}^{\mathrm{a}}$ \\
\hline & Retain habitat area ( $70 \%$ of natural scenario) & Constraint & Goal $^{\mathrm{a}}$ \\
\hline & Maintain closing inventory growing stock & Constraint & Goal $^{\mathrm{a}}$ \\
\hline & Increase red and white pine growing stock & Constraint & Goal $^{\mathrm{a}}$ \\
\hline & Limit the proportion of silviculture treatment intensities by forest type & Constraint & $\mathrm{Goal}^{\mathrm{a}}$ \\
\hline \multirow[t]{3}{*}{ Spatial } & Defer designated marten core areas from harvest & Constraint & Constraint \\
\hline & $\begin{array}{l}\text { Implement an appropriate frequency and size class distribution of } \\
\text { harvest opening sizes }\end{array}$ & $\mathrm{n} / \mathrm{a}$ & Goal \\
\hline & $\begin{array}{l}\text { Move towards a landscape pattern that fits the natural disturbance } \\
\text { pattern emulation template }\end{array}$ & $\mathrm{n} / \mathrm{a}$ & Goal \\
\hline \multirow[t]{3}{*}{ Operational } & Include only stands that have road access in those eligible for harvest & $\mathrm{n} / \mathrm{a}$ & Constraint \\
\hline & $\begin{array}{l}\text { Consider transportation budget (construction, hauling and maintaining) } \\
\text { while allocating harvest }\end{array}$ & $\mathrm{n} / \mathrm{a}$ & Goal \\
\hline & $\begin{array}{l}\text { Allow the most intensive silvicultural treatments to occur only near } \\
\text { major road corridors }\end{array}$ & $\mathrm{n} / \mathrm{a}$ & Constraint \\
\hline
\end{tabular}

aThe target levels associated with these objectives were initialized in Patchworks based on SFMM scoping analysis. 
tially, only the non-spatial objectives were represented in the Patchworks model. This confirmed that, in the absence of spatial criteria, SFMM and Patchworks predicted similar levels of achievement for many of the sustainability indicators. The SFMM model had fewer constraints and identified the optimal aspatial solution, defining the upper limit of what the Patchworks solution could approach but not surpass. Differences in the model formulations (e.g., spatially explicit constraint of allocating by polygon), and limitations of the heuristics and the length of time allowed to converge on a solution, resulted in slightly lower levels of achievement in Patchworks compared to SFMM for some targets. Over a number of scenarios, analyses indicated that Patchworks could achieve many of the targets individually but could not achieve them all simultaneously. The weight values used in the goal programming formulation were iteratively adjusted to reduce specific deficits, but some values were mutually exclusive, and as one target was favoured another would decline. Balanced solutions that spread the shortfall over multiple targets achieved harvest levels that were approximately $0.6 \%$ lower in the initial periods of the simulation (rising to meet the targets in the final periods).

Spatial and operational objectives were incorporated into subsequent modelling scenarios leading to the development of the LTMD. At this stage, the planning team selected a Patchworks scenario that represented an acceptable balance among objectives. Compared to the conventional modelling approach, spatial considerations in the pilot approach were being addressed in strategic-level decision-making. The spatial objectives were additional constraints to the system, and as such were expected to reduce the aspatial indicators determined using SFMM. Results were similar to the previous aspatial step: targets were reduced and weight values were adjusted to ameliorate specific shortfalls. After a number of iterations, a balanced scenario was designed that met key biodiversity objectives and achieved $98.2 \%$ of the wood supply goals for the first planning period, again improving over later periods.

Unlike the conventional modelling approach (Fig. 1), tactical-level decision-making begins with a strategic solution that includes a number of spatial and operational planning considerations. Tactical planning using Patchworks involves the refinement of the 10-year harvest schedule associated with the LTMD solution. Specifically, refinements address logging chance factors and tactical considerations that were not or could not be fully considered in the LTMD (i.e., balancing wood quality, detailed operational factors such as soil type, seasonal restrictions, water crossings, silvicultural considerations, inventory error, etc.). Refinements were made by adjusting targets, or by assigning fixed treatments or deferring areas from harvest. As these decisions are incorporated into the spatial model, other strategic targets associated with the LTMD may change. The change in strategic targets will likely vary by forest and model formulation and will also depend on the degree to which operational considerations were included in the model. It is expected, however, that at this level of detail, decisions to defer or expedite harvest blocks by a few planning periods will not significantly affect strategic indicators. The clear advantage of the Patchworks implementation is that the long-term effects of the operational adjustments are evaluated comprehensively and immediately.
The following is an overview of the process used for operational refinement of the LTMD using Patchworks.

1. As a first step, the harvest schedule associated with the strategic LTMD is provided to operations personnel for review. An operational review of this harvest schedule is generally focused on 3 primary objectives:

- To confirm that scheduled harvest blocks are acceptable/desirable for operations plan.

- To identify scheduled harvest blocks that are not acceptable/desirable for operations.

- To identify unscheduled blocks that should be scheduled for harvest operations.

2. The harvest scheduling parameters in the model are modified to reflect proposed operational decisions:

- Accepted harvest blocks are "fixed" in the model. This means the scheduled treatment is forced to happen in the operational period (first or second 5-year period).

- Unaccepted harvest blocks are "deferred." This means that these blocks are precluded from being scheduled by the model during the operational period.

- Selected blocks that are to be added to the schedule are "fixed" and become "forced treatments."

3. The model is re-solved with target parameters from the strategic LTMD. The levels of achievement associated with the "refined" solution are assessed against the strategic LTMD levels. Changes in levels are either rationalized or specific adjustments to the operational plan are identified.

4. The "refined" solution and/or adjustments (step 3) are sent back to an operational review and steps 2 and 3 are repeated until an operational plan is completed.

The refined solution and the associated change in strategic levels are made available to the planning team at regular intervals during this process. Operational refinement is complete once a feasible operational plan is developed and deviations from the strategic-level targets are accepted by the planning team. The final model scenario resulting from the refinement process is the LTMD for the forest management plan and is the modelling outcome that is ultimately documented in the final FMP. Once the operational LTMD is complete, some minor manual/GIS-type modifications may be required to finalize operational prescriptions.

\section{Technical Issues}

The conventional hierarchical process can be improved using modelling tools that provide consistency of assumptions between the hierarchical process levels. The pilot implementation improves integration to the extent that the information passed between the planning levels is consistent and based on the same set of assumptions. However, Patchworks and SFMM have a number of fundamental implementation differences due to the nature of their design, and ultimately from the differences in how each model is constructed to approach problem-solving (Table 2). Here we describe key differences between the aspatial and spatial models and the effects on their forecasts.

\section{Unit of analysis and response rules}

Perhaps the most significant difference between the models is the fundamental unit of analysis and how assumptions of forest dynamics are represented. In SFMM, data are aggregated 
Table 2. Summary of major differences between the Strategic Forest Management Model (SFMM) and Patchworks

\begin{tabular}{lll}
\hline Characteristic & SFMM & Patchworks \\
\hline Unit of analysis & $\begin{array}{l}\text { Area stratified and summarized by forest } \\
\text { type and age class }\end{array}$ & Polygons classified by forest type and age \\
\hline $\begin{array}{l}\text { Complexity of succession and response } \\
\text { to treatments }\end{array}$ & $\begin{array}{l}\text { Areas may succeed or renew to multiple } \\
\text { forest types and ages }\end{array}$ & $\begin{array}{l}\text { Area must renew or succeed to a single forest } \\
\text { type and age }\end{array}$ \\
\hline Formulation & $\begin{array}{l}\text { Optimize single objective subject } \\
\text { to constraints }\end{array}$ & $\begin{array}{l}\text { Solve for multiple objectives using goal } \\
\text { programming }\end{array}$ \\
\hline Solver & Linear programming & Stochastic meta-heuristic \\
\hline
\end{tabular}

by strata and age class, whereas as a spatial tool like Patchworks must track the age, stratification, and area of each distinct polygon. In SFMM, dynamics can be expressed as forestwide proportions and implemented using fractional transfers of area among strata and age classes. Thus, uncertainty can be described using simple deterministic rules. For example, the response to a harvest treatment could be that $80 \%$ of the area treated in a forest unit regenerates to the target forest type and $20 \%$ of the area regenerates to an alternate forest type (see Fig. 4a). Significantly more complex rules are used in practice, reflecting a high level of natural variability and a low level of confidence about site-level predictions. On the other hand, by design the spatial model is constrained to maintain each polygon as a distinct unit composed of homogeneous forest cover and uniform age structure. Since polygons can only be characterized as belonging to 1 forest stratum and 1 age class, multiple response rules are not allowed. To provide consistency between the 2 models for the pilot study analysis, the approach used was to stratify the initial forest in proportion to the response rules, and then apply a single rule to each subdivision (see Fig. 4b).

Ideally, the subdivision of strata and apportionment to response rules would be objectively based on physical site characteristics determined from collateral geographic data sets. For example, jack pine stands on sandy outwash sites usually regenerate successfully to jack pine but on nutrientrich upland sites competition may lead to intolerant species. A GIS overlay operation that imposed surficial geology on forest cover would help to discriminate successional processes. Unfortunately, the available forest inventory did not contain the attributes required to make these decisions and time allocated to the project was insufficient for collecting new data. A simple alternate approach was developed to assist in the stratification of forest units for post-renewal pathways using a silvicultural treatment response apportioning program (STRAP). STRAP was intended to augment stratifications made by planners based on expert opinion by randomly allocating deterministic pathways to polygons based on SFMM's proportional response rules (e.g., forestlevel averages). The STRAP approach was applied to the Romeo Malette forest inventory to generate the types of substratifications illustrated in Fig. 4b.

\section{Goal programming formulation}

Another key difference between Patchworks and SFMM is their fundamental model formulation. Patchworks uses a goal programming (GP) formulation (Lee 1972) to address a mul-

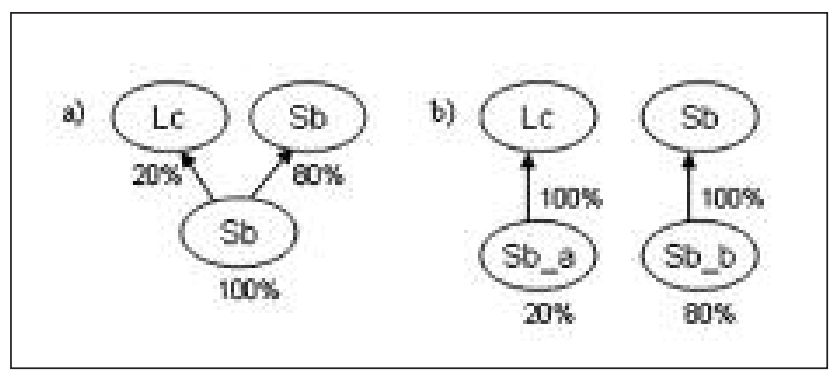

Fig. 4. The aspatial model allows multiple response rules to succession or treatment events (a) and the area is proportionally assigned to the new classes. The spatial model allows only a single transition. To compensate, the initial areas are subdivided and pre-assigned to the appropriate response classes (b) for use in the spatial model. In this example, Sb and Lc represent the black spruce and lowland conifer forest units respectively.

tiple objective planning problem, and SFMM uses linear programming (LP) formulation to optimize a specific objective function subject to constraints (although SFMM is capable of implementing a GP formulation, this option is rarely used in practice).

The advantage of the GP approach is that it allows multiple goals to be expressed simultaneously, and allows the model to find an outcome where the goals may be in competition with each other. This style of modelling allows for an improved integration of management concerns, since multiple objectives can "trade off" to equilibrium between scarce resources. This feature addresses a frequent criticism of the forest planning process that non-timber objectives have been treated as constraints while timber values are optimized. The GP formulation allows multiple goals representing a variety of competing interests to effectively participate in the modelling process, which can facilitate trade-off analyses by the planning team.

\section{The Patchworks solver}

Patchworks also differs from SFMM in the solver that is used to generate management sequences. SFMM uses a mathematics programming solver to solve a finite series of simple constraints, each expressing a part of the abstract model. The techniques used are mathematically robust and limited only by computational power, which is more than ample in typical desktop computers. The results produced by the LP/solver combination are unequivocal and verifiable. If a feasible solu- 

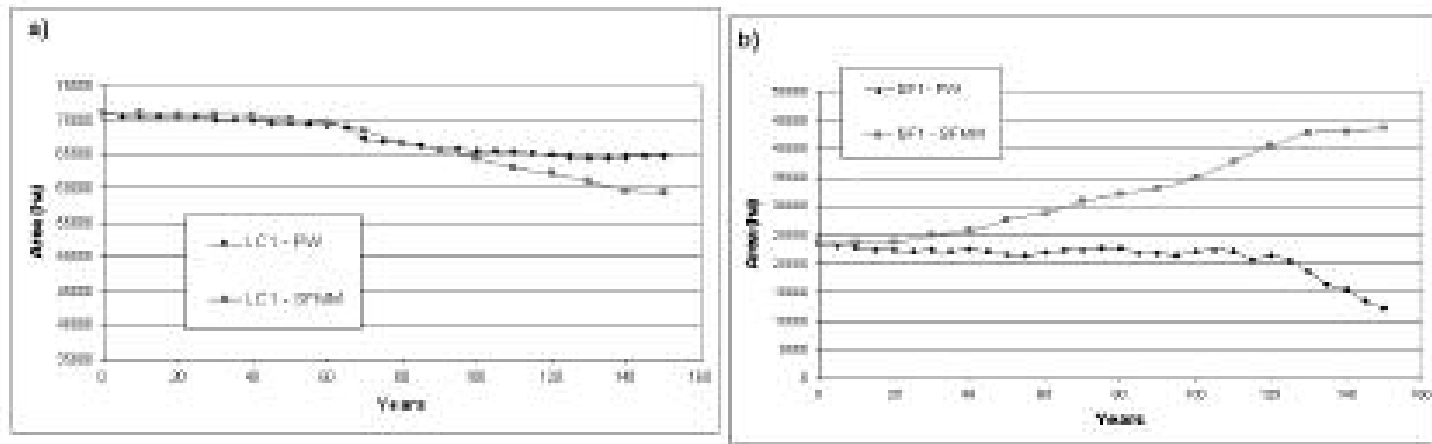

Fig. 5. Summaries of Strategic Forest Management Model (SFMM) and Patchworks (PW) forecasts of area over time for the lowland conifer (LC1) and spruce-fir (SF1) forest units in the Romeo Malette Forest for simulations with identical inputs (a) with simple succession rules and (b) with more complex rules. In the absence of harvest, the lines diverge due to differences in the treatment of succession.

tion can be found, the solver will determine an exact combination of inputs required to achieve the optimal objective function value.

The spatially explicit formulation in the Patchworks model is similar to a mixed-integer program, a type of problem that could theoretically be solved using LP. However, due to the large number of interdependencies required to represent the spatial aspects of the problem, the number of steps required increases at a greater than polynomial rate with each additional problem element. This type of problem is classed as NP-hard (Cormen et al. 2001), and with the excessive time and space requirements is not amenable to exact solutions using LP algorithms. As an alternative, Patchworks uses a set of stochastic meta-heuristics to identify a good approximation to the optimal solution in a reasonable amount of time (for a general description of the algorithms, see Lockwood and Moore 1993). The solver sequentially works through tens of millions of possible management plan options, each feasible and better than the previous one. As the number of iterations increases, the solutions will improve to the point where they are reasonable. Due to the exceptionally large solution space involved, the search needs to be terminated prior to stabilization, and it is unlikely that the solver will have found the "true optimum solution." However, the model very quickly generates solutions that we expect are within a narrow margin of the true optimum (although this can never be verified, since the true optimum value for the type and size of combinatorial problem we are trying to solve can never be known). The variance of the final solution from the true optimum is more than overshadowed by the error and uncertainty in our assumptions about the biological system. Spatial modelling using these methods accepts an implicit compromise that the utility that is lost from not having an exact optimum solution is compensated by having a solution that is developed with consideration of operational forest policies.

Since the Patchworks solver employs stochastic methods, the outcomes of 2 identical simulations started using a different seed in the random number generator will be slightly different. One of the implications is that differences in outcomes of simulations with only small differences in target values may be obscured by random effects. This effect is counterintuitive and disconcerting to analysts who are used to the deterministic and predictable outcomes from LP models.

\section{Influence of model differences on results}

The differences between the design, capabilities, and behaviours of the 2 models resulted in differences in the forecasts and solutions produced. Like all forecasting models, Patchworks requires the initial conditions of the forest and a set of rules that describe how the system changes through time as inputs. Although we used the same initial data sets and management options in both models, subtle differences in model implementation and capabilities meant that the resulting predictions were not identical. Discrepancies were found in the initial area estimates, in the treatment of succession and response to treatments, and in the modelling of natural disturbance events.

Both models recorded the same area by forest unit at time zero (initial conditions, prior to management actions or other change). The initial area available for harvest was less in Patchworks since deductions were recorded up front to account for areas reserved from harvest (primarily to account for within-block retention), whereas the SFMM model accounted for these deductions only when the area was selected for harvest. The area by age class differed in the Patchworks model, as polygons ages were adjusted to be younger than the single succession age for the polygon. This adjustment was necessary so that renewal events would be applied correctly for stands that were already older than the breakup age.

As the simulation time progressed, the forecasts of forest unit area developed by the 2 models began to diverge, even in the absence of any management actions (Fig. 5). The differing implementation of the succession and post-treatment response rules resulted in transfers of area to different forest units and age classes as the simulation progressed. The indicators for habitat and old-growth also diverged, since these were associated with forest unit and age class. These effects varied by forest unit and depended on how the response rules had been translated between the 2 models. Where the 
response rules were simple to start with, and the translation to Patchworks was congruent, the difference was limited (Fig. 5a). Where the rules were complex and the translation was simplified, the differences became more noticeable (Fig. 5b).

The area allocated for harvest in the first period differed between the models (Fig. 6), even though the objectives and outcomes were almost identical. It appears that the surface of the objective function is large and flat and many different harvest allocation configurations can achieve substantially the same outcomes. This supports the idea that the AHA may not be the best link for connecting the strategic and tactical planning levels. The aspatial targets can be reasonably met by a variety of AHA and spatial configurations, but some spatial configurations may be much better suited to achieving the spatial objectives that are considered at the tactical level.

Natural disturbance through fire, insect outbreaks, weather events, and other causes is an important agent of change in the boreal forest. Management optimization models typically use deterministic methods to represent random and fluctuating natural phenomena, trading off realism for convenience. The SFMM model uses regular and uniform depletion of areas to simulate the occurrence of natural disturbance events. The disturbance events are selected from forest unit categories representing the whole forest, so the location of specific events is not an issue for the algorithm. The Patchworks model is spatial, so the "forest-wide proportional loss" technique used in SFMM would mean that all polygons would be proportionally depleted in each planning period. Patchworks could implement a stochastic polygonbased disturbance mechanism, but problematic interactions would occur where the solver would attempt to schedule harvests treatments just prior to a disturbance event to minimize losses. Neither of these options provides a realistic portrayal,

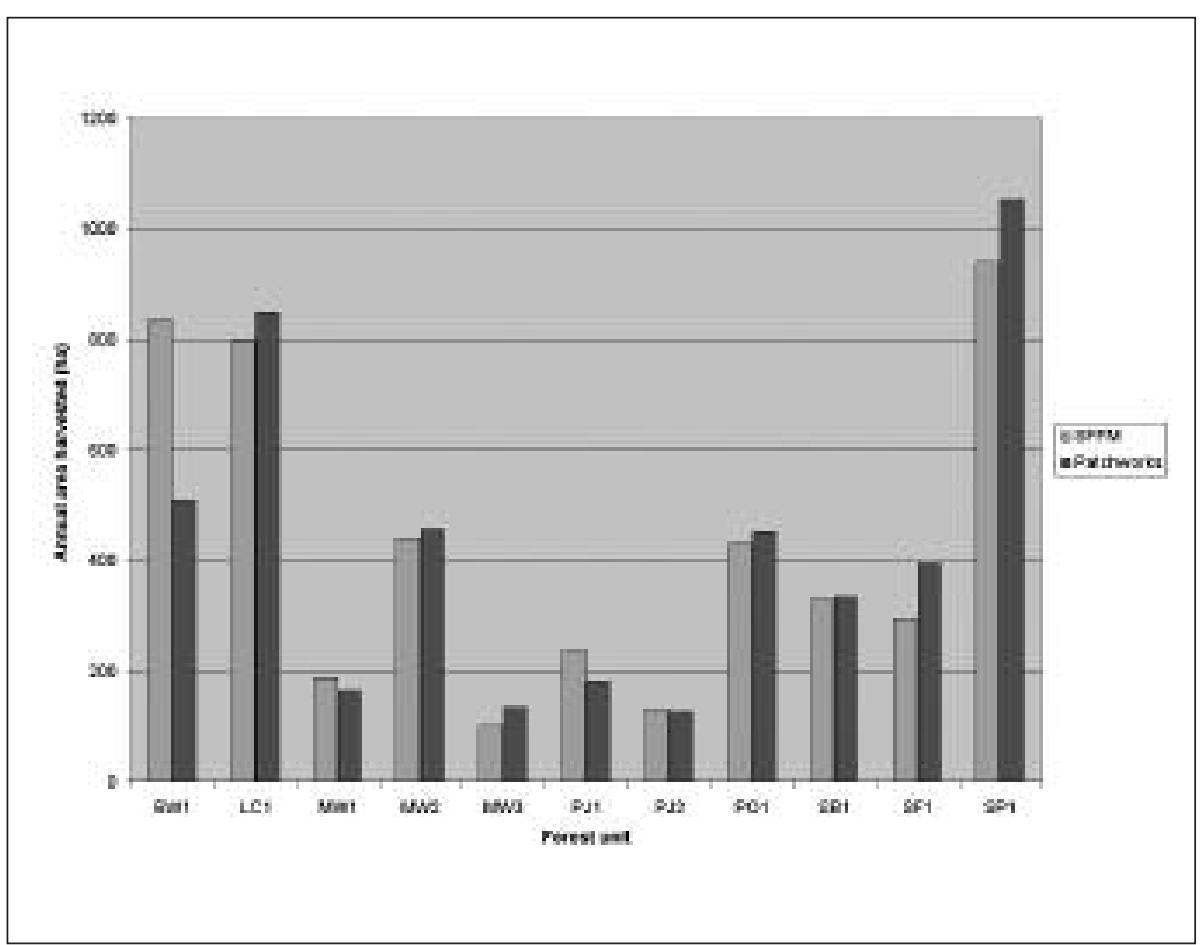

Fig. 6. Differences in annual harvest area allocated using the Strategic Forest Management Model (SFMM) and Patchworks for the Romeo Malette Forest in the first planning period so the explicit design decision was to exclude natural disturbance dynamics from Patchworks. Consequently, the SFMM and Patchworks forecasts differed due to the different mechanisms for handling effects of natural disturbance.

\section{Process and Organizational Issues}

Perhaps one of the more obvious FMP process challenges arises from the fact that Patchworks modelling spans the gap between the strategic and tactical planning levels. In an FMP process that has co-evolved with the SFMM model, the requirements for staged plan review and public consultation depend on this separation in analyses, where strategic modelling stops and tactical planning begins. The direct link between strategic achievement and spatial allocations provided by Patchworks challenges conventional concepts engrained in the planning process, such as the AHA. Conventionally, the AHA and associated projections such as forest area, habitat, and volume through time represented the end of strategic planning. Staged review and public consultation served to "freeze" this strategic direction early in the planning process. The introduction of Patchworks modelling at the strategic planning level changes the nature of modelling products conventionally available at this stage of planning and introduces a continuum of modeling from strategic through tactical. This resulted in decisions about target levels being revisited and revised repeatedly, to the discomfort of some planning team members who would have preferred quick and definitive closure on key decisions.

The hierarchical modelling approach using Patchworks promotes a continual refinement of strategic level projections. The strategic LTMD solution forms a point of reference for subsequent analysis that supports increasingly finer-scale decisions. The concept of continual refinement means that conventional modelling products such as the AHA are dynamic until tactical planning is complete. The significant procedural difference is that the AHA becomes an outcome of the tactical process that corresponds exactly to the spatial allocation and is no longer a strategic planning product used to constrain the spatial allocation of harvest areas. To remain confident that the changes to the tactical allocation are without bias, the process may need to change so that the planners record the rationalizations for their tactical adjustments, and the regulators can audit these choices.

An important side effect of the continual refinement process is that strategic-level indicators change throughout the planning process. To some, this is seen as improved transparency in the planning process and reflects the fact that short-term operational decisions can affect long-term strategic indicators. This transparency, however, brings with it 
the responsibility to decide on acceptable levels of variation in these indicators, and monitor and assess these changes at each stage of the planning process. To others, this is added complexity in the process that generates conflict and confusion during public review. In this pilot, we briefly examined multiple-criteria decision-making ( $\mathrm{MCDM}$ ) techniques to assist in this review-this is an area for further exploration and development.

The investigational nature of the hierarchical modelling approach was a learning experience and was endorsed by the planning team under this pretext. The lack of a prescribed process and vision for the hierarchical modelling approach in the FMP process generated differing expectations and levels of understanding. This uncertainty expressed itself at different organizational levels in the planning team and with collaborators (for example, when choosing subjective weighting values in the goal programming formulation). The lack of common expectations and a shared vision contributed to difficulties in reaching key milestones in the decision-making process.

The type of decision support afforded by Patchworks is substantially different from that of SFMM. The GP approach in Patchworks requires a stated set of preferences (or weights) that describe how competing goals should be favoured. Since preferences for non-substitutable outcomes (e.g., more wood versus better conservation) are subjective rather than objective it is easy to state a set of preferences, but it may be difficult to get all stakeholders in the management process to agree to the weighting among goals. Typically, a trade-off analysis conducted with a GP model will require a carefully designed series of simulations that explore the range of possible trade-offs by systematically altering goals and weights. This process was difficult for the planning team since changes to goal preferences for one goal often resulted in changes to the level of achievement of many other goals. This characteristic of the GP approach required the planning team to undertake a complete review of all targets in each simulation to assess shortfalls to the suite of management targets. Since the Romeo Malette Forest model had nearly 75 individual management targets spanning 30 planning periods, this required evaluating changes to 2250 decision attributes. This required additional effort for reviewing scenarios and obliged the planning team to deal with questions about how much deviation was allowed for each target and timeframe. This differed from the conventional process, where most management targets would be set as constraints during the strategic analysis, and rarely reviewed again regardless of the impacts at the tactical level.

Another area of consideration surrounded the transfer of management targets from SFMM to Patchworks. Despite the subtle implementation differences between the 2 models, as discussed in the previous section, non-spatial targets generated in SFMM were used in Patchworks without any adjustment. It was expected that the spatial representation, as well as the additional spatial management objectives, would reduce the maximum potential level of achievement for nonspatial targets. Due to the novelty of the process there was no pre-established understanding of what was an acceptable level of variance, and this required the planning team to once again break new ground on questions of a subjective nature.

The long history and significant training investment in using SFMM in FMPs has generated a broad user base with a high level of competency in this technology, and has estab- lished the SFMM modelling paradigm as the common language for analysis in Ontario. Patchworks, on the other hand, is a relatively new tool in Ontario, with fewer analysts having a similar competency and understanding. The planning team needed to discuss and resolve issues of how the technology worked as well as the resource management concerns, which increased the demands on their time. The Forestry Research Partnership (CEC-FRP; Bruemmer 2008, this issue) has been a major contributor to the implementation of spatial modelling by funding a series of introductory projects, including this implementation pilot. Part of this pilot included support for a spatial modelling expert who described the capabilities of the model, set up the data sets, ran the simulations, and helped to explain and interpret the output. It appears as though the spatial modelling skills are sufficiently specialized at this time that it is unreasonable to expect planning foresters and biologists to perform these functions until further training and more specific guidelines are provided. It is clear from our experience that at the present time at least one experienced spatial analyst should be dedicated to the planning team to carry out these tasks and to provide interpretation and training for other planning team members.

A number of web-based collaborative techniques were used to improve communications among team members, including remote screen-sharing technology, online collaborative discussion forums, and web-based delivery of simulation results. If a picture is worth a thousand words, then the remote desktop-sharing technology was invaluable to help communicate complex ideas in a subject area where everyone was learning the vocabulary and concepts. The online discussion forums seemed to work well initially to provide a common location and archive of draft documents and minutes of meetings. However, as the planning process progressed, the use of the forum dwindled. The web-based delivery of simulation results provided a hyper-linked set of model outputs available to all team members. This aspect of the web-based collaboration effort was most successful, allowing planning team members to access and explore model results, independently, as they were produced.

\section{Lessons Learned}

Pilot implementation of the hierarchical modelling approach, which involved a combination of aspatial and spatial models, has been a valuable learning experience for all project collaborators. Interestingly, the learning was asymmetric: technically oriented individuals needed to learn more about process issues and planners needed to learn more about technical details.

At the time of writing, the planning team had developed and agreed on a Patchworks-based LTMD for the plan. The planning team was beginning stage 2 public consultations and was in the early stages of operational refinement of the LTMD solution. The most critical time to gauge the overall success of the hierarchical modelling approach was quickly approaching. Though it is somewhat premature to discuss success or failure, several important observations are possible based on experiences to date. A short list of lessons learned during early implementation of the hierarchical modelling approach for the Romeo Malette Forest is:

- Planning workloads shifted - Use of a spatial model shifted modelling effort to an earlier stage of the FMP 
process. More time was spent by planners exploring the effects of the spatial objectives and adjusting other targets to find a balanced solution. It is anticipated that this cost will be compensated by reducing the time required to develop the operational plan because many locational issues had already been addressed within the model. However, the fixed timetable of the FMP process meant that more work had to be carried out in the same limited amount of time.

- Better forest inventory data needed - Non-spatial models use aggregated summaries of forest unit areas, whereas spatial models required polygon-level estimates. Although inputs for both models were generated from the same forest inventory data, members of the planning team were generally less confident with results generated from detailed forecasts of polygon-level development than they were with aspatial forest predictions. It is clear from this FMP that full use of a spatial modelling approach (e.g., developing operational allocations) depends heavily on the quality of the inventory.

- Computational time increased - Spatial modelling data sets are larger and processing times to run a scenario are longer than those for conventional modelling. With the increased processing workload it is not practical with current computer power to adjust and assess multiple modelling scenarios over the course of a 2-day, face-to-face planning team meeting, as occurred with the aspatial model. Web-based collaboration, however, mitigates this to some degree by providing instantaneous access to model results and the ability to communicate issues and adjustments outside face-to-face meetings.

- Changes in FMP process needed - Fundamental aspects of the planning process were altered in the pilot implementation. Among the most significant were including spatial policy direction directly in management strategy development and the lack of a clear break between strategic and operational planning. These modifications caused a significant departure from conventional processes and concepts such as available harvest area. Expectations about modelling products and progress check points need to be clearly understood before the decision-making process begins.

- More effort needed to transfer goal programming approach - The nature of the results produced by the spatial model required that planners subjectively assess model results. As a result they had to make decisions about the tolerances for specific targets very early in process, to the discomfort of some. More effort is needed to establish proper understanding of how goal programming works, including the development and transfer of support tools to more quickly and objectively assess management scenarios.

Implementation of a new technology into a highly regulated organizational process requires team work, collaboration, and a spirit of innovation. Many challenges have been addressed in this implementation project that could not have been overcome without the cooperation of key planning team members and advisors. Issues such as the increased resolution of the model and changes in conventional concepts and procedures have challenged the planning team to adjust and adapt. In each of these cases, planning team members have persevered with the belief that this approach provides a signif- icant improvement to forest management planning and will increase confidence in the overall sustainability of the longterm management direction.

The operational factors included in the spatial model should lead to strategic and tactical plans with characteristics that support long-term sustainability for economics as well as fibre supply and biodiversity. Unfortunately, improvement to the planning process cannot be experimentally tested as 2 alternate management styles cannot be implemented and measured on the same forest. However, based on their experience in previous planning exercises, the consensus from planning team members is that the new process has increased their confidence that a realistic and predictable harvest will be available in future planning periods.

The pilot implementation required more work by analysts and planning team members, and was thus more expensive than the conventional process. Much of our time was spent developing and refining procedures, so we expect the next application to be more efficient, especially if training is provided to the same level as with the aspatial model. Besides the improvements in confidence and reliability, plans developed with consideration of operational factors have the potential to achieve savings by lowering long-term operating costs. Unfortunately, we cannot conceive of a practical method to measure these cost savings, since there is no way to replicate the "with spatial planning" and "without spatial planning" trials in a meaningful way.

Large and entrenched organizational processes such as Ontario's FMP process have significant legislative and regulatory requirements and are difficult to change. This implementation pilot has facilitated a case study of fitting a new technology within the existing system. The lessons learned from the approach being "patched" together in this FMP have helped to break new ground for future planning teams to take advantage of the many benefits of a decision support system that includes spatial modelling.

\section{Acknowledgements}

The authors would like to thank the Romeo Malette Forest planning team members for their patience and willingness to participate in the pilot project while still carrying on their regular duties. We also thank the Northeast Core Team for facilitating the technology transfer effort, and to Sue Pickering and the Forestry Research Partnership for providing leadership in this exercise. We also wish to acknowledge the Enhanced Forest Science Program for providing partial funding for this work.

\section{References}

Anthony, R.N. 1965. Planning and Control Systems: A Framework for Analysis. Harvard University Graduate School of Business Administration, Boston, MA.

Beale, E.M.L. 1968. Mathematical Programming in Practice. Pitman, New York.

Boston, K. and P. Bettinger. 2001. Development of spatially feasible forest plans: a comparison of two modeling approaches. Silva Fenn. 35(4): 425-435.

Bruemmer, G. 2008. The Forestry Research Partnership: Developing the partnership. For. Chron. 84(5): 648-652.

Bunnell, F.L. and M. Boyland. 2003. Decision-support systems: it's the question not the model. J. Nature. Cons. 10: 269-279. 
Cormen, T., C.E. Leiserson, R.L. Rivest and C. Stein. 2001. Introduction to Algorithms, Second Edition. MIT Press and McGrawHill, New York.

Davis, R. 1999. Strategic Forest Management Model Version 1.6 User Guide. Ont. Min. Nat. Resour., Toronto, ON. 270 pp.

[FSCWG] Forest Stewardship Council Canada Working Group. 2004. National Boreal Standard. FSC Canada, Version 3 [online]. Available at http://www.fsccanada.org/NationalBoreal.htm [Accessed May 2008).

Gunn E.A. 2005. Sustainable forest management: Control, adaptive management, hierarchical planning In M. Bevers and T.M. Barrett (comps.). Systems Analysis in Forest Resources: Proceedings of the 2003 Symposium. USDA For . Serv., Pac. Northw. Res. Sta., Portland, OR. PNW-GTR-656.

Lee, S.M. 1972. Goal Programming for Decision Analysis. Auerbach Publishers, Philadelphia, PA.

Lockwood, C. and T. Moore. 1993. Harvest scheduling with spatial constraints: a simulated annealing approach. Can. J. For. Res. 23: 468-478.

McPherson, S. F.W. Bell, J. Leach, P. Street and A. Stinson. 2008. Applying research for enhanced forest productivity on the Canadian Ecology Centre - Forestry Research Partnership forests. For. Chron. 84(5): 653-665.
Moore, T. and G. Tink. 2008. Technical considerations in the design of core habitat patches in forest management: A case study using the Patchworks spatial model. For. Chron. 84(5): 731-740.

[OEAB] Ontario Environmental Assessment Board. 2003. Declaration order regarding MNR's Class Environmental Assessment Approval for Forest Management Planning on Crown Lands in Ontario, MNR-71. Ont. Environ. Assess. Board, Toronto, ON.

[OMNR]. Ontario Ministry of Natural Resources. 2001. Forest management guide for natural disturbance pattern emulation (version 3.1). Ont. Min. Nat. Resour., For. Manage. Br., Sault Ste. Marie, ON. 440 p.

[OMNR]. Ontario Ministry of Natural Resources. 2004. Forest management planning manual for Ontario's Crown forests. Ont. Min. Nat. Resour., Toronto, ON. 440 p.

Simon, H.A. 1972. Theories of Bounded Rationality. In C.B. McGuire and R. Radner (eds.). Decision and Organization. pp. 161-176. North-Holland Publishing Company, Amsterdam.

[SPS] Spatial Planning System. 2008. Patchworks User Guide. Spatial Planning Systems, Deep River, ON. 